\title{
CSHP Summer Educational Sessions (SES) 2015: Poster Abstracts / Séances éducatives d'été (SÉÉ) 2015 de la SCPH : Résumés des affiches
}

\section{CSHP 2015}

CSHP 2015 is a quality program that sets out a vision of pharmacy practice excellence in the year 2015. Through this project, CSHP challenges hospital pharmacists to reach measurable targets for 36 objectives grouped under 6 goals, all aimed toward the effective, scientific, and safe use of medications and meaningful contributions to public health. CSHP 2015 applies to inpatients and outpatients, community and hospital pharmacists, and all practice settings. Posters identified with a "CSHP 2015" logo are those judged by the CSHP 2015 Steering Committee to be particularly relevant to one or more of the 36 objectives.

\section{SCPH 2015}

Le projet SCPH 2015 est un programme axé sur la qualité qui propose une vision de l'excellence en pratique pharmaceutique en l'an 2015. Au moyen de ce projet, la SCPH met les pharmaciens d'établissements au défi d'atteindre les cibles mesurables de 36 objectifs répartis entre 6 buts, visant tous l'utilisation efficace, scientifique et sûre des médicaments ainsi que des contributions significatives à la santé publique. Le projet SCPH 2015 s’applique aux patients hospitalisés et externes, aux pharmaciens d'hôpitaux et communautaires, et à tous les milieux de pratique. Les affiches marquées du logo "SCPH 2015 " sont celles que le Comité directeur du projet SCPH 2015 a jugé particulièrement appropriées à l'un ou l'autre des 36 objectifs.

The texts of poster abstracts are published exactly as submitted by the authors and have not undergone any copyediting by the Canadian Journal of Hospital Pharmacy

Le Journal canadien de la pharmacie hospitalière n'a pas soumis le texte des résumés des affiches à une révision linguistique et les publie ici tels que remis par les auteurs.
Sunday, August 16, 2015 • Dimanche 16 août 2015

Facilitated Poster Sessions: Discussion of Original Research and Pharmacy Practice Projects

Séance animée de présentations par affiches: Discussions sur des projets de recherche originale et des projets dans le domaine de la pratique pharmaceutique

Safety

1. Evaluation and Validation of Pictograms about how to Make Medications Taste Better

2. Variation in Antiretroviral Concentrations during Acute Hepatitis C: A Case Report

3. Evaluating Recall of Key Safety Messages, Attitudes and Perceptions of Patient Safety Initiative

4. Persistence and Compliance with Cardiovascular Drug Therapy among Seniors

5. Preventable Medication Incidents: Look-Alike/Sound-Alike Drug Names

\section{Pharmacy Practice}

1. Revising the GRASP® Workload Measurement Tool to Track Clinical Pharmacy Key Performance Indicators

2. The Development of an Advanced Pharmacy Practice Experience in Pharmacy Informatics

3. Evaluation of an Educational Intervention for Pharmacist Documentation Practices in a Tertiary Care Hospital

4. Critical Care Pharmacist Pilot Project

5. Developing and Implementing a Vision for Clinical Communication Using Pharmacy Information Systems in Hospitals

6. Pre-operative Study Evaluating Patient Complexity with a Novel Pharmacy Triage Tool

Monday, August 17, 2015 • Lundi 17 août 2015

1. Evaluation of a Provincial Hospital Formulary Review Process

2. Impact of PharmaNet-Based Admission Medication Reconciliation on Warfarin Best Possible Medication Histories

3. Restriction of Codeine Prescribing in Patients Less than 18 Years Old: Policy to Provide Safer Pain Management in Paediatric Population

4. Incidence, Management and Sequelae of Out-of-range INR Values in a New Anticoagulation Clinic in Qatar

5. Development of an Educational Program for Hospital Pharmacists Focused on Drug Information and Evidence-Based Medicine

6. Development and Evaluation of an Anticoagulation Education Resource for Patients

7. Feasibility of Monitoring Real-Time Temperatures of Medications in a Ground Ambulance System: A Pilot Study

8. Community Pharmacist Perception and Utilization of a Pediatric Emergency Department Asthma Action Plan and Prescription

9. Tolerability and Efficacy of Basiliximab as Induction Therapy to Prevent Cardiac Transplant Rejection: A Systematic Review 


\section{Evaluation and Validation of Pictograms about how to Make Medications Taste Better

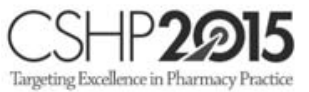

Villarreal G, Vaillancourt R, Karmali S, Kraft A, Pouliot A Department of Pediatrics, Pharmacy, Children's Hospital of Eastern Ontario, Ottawa, ON

Background: It can be challenging to administer medications that taste unpleasant to children. This can often result in low adherence rates. Furthermore, studies have shown that health literacy is an important factor in patient understanding of conveyed health information. Pictograms (illustrated representations of certain actions), are useful tools that can help improve adherence by conveying information to patients with low health literacy.

Purpose: To evaluate and validate a set of pictograms describing how to make medications taste better for children.

Method: We consecutively recruited children ages 9 to 17 years old, and parents/caregivers over 18 years old, from the waiting rooms at the Children's Hospital of Eastern Ontario. Using translucency and transparency questions in structured one-on-one interviews, we tested the comprehensibility of 12 pictograms that described how to make medications taste better for children. A pictogram is considered validated when at least $85 \%$ of participants correctly guess the meaning of the pictogram. To numerically measure the extent to which participants associated an image with its intended meaning, a translucency test was administered. Short-term recall was evaluated by requesting participants to reiterate each pictogram's meaning, following two distractors.

Results: A total of 51 children participated in the study. Initially, 6 out of 12 pictograms successfully conveyed their messages; following shortterm recall, 12 out of 12 successfully conveyed their messages. According to the visual analog scale rankings, most participants believed the pictograms depicted what they were supposed to portray, after being told the meanings.

Conclusion: The validated illustrations can now be added to pharmaceutical labels to instruct parents on how to make their children's medications taste better.

\section{Variation in Antiretroviral Concentrations during Acute Hepatitis C: A Case Report}

\author{
Raiyani $D^{1}$, Sheehan $N^{2,3}$, Wong $A^{4}, N_{g o} H^{5}$, Wong $D^{5}$, Kovacs $C^{6}$, \\ Tseng $A^{1,5}$ \\ ${ }^{1}$ Leslie Dan Faculty of Pharmacy, University of Toronto, Toronto, ON \\ ${ }^{2}$ Chronic Viral Illness Service, Montreal Chest Institute, Montréal, QC \\ ${ }^{3}$ Faculté de pharmacie, Université de Montréal, Montréal, QC \\ ${ }^{4}$ Pharmacy Department, McGill University Health Centre, Montréal, QC \\ ${ }^{5}$ Toronto General Immunodeficiency Clinic, Toronto, ON \\ ${ }^{6}$ Maple Leaf Medical Clinic, Toronto, ON
}

Background: Acute viral hepatitis has been shown to affect metabolism of various drugs such as diazepam and methadone, but data on the impact of acute hepatitis $\mathrm{C}$ infection on antiretroviral drug (ARV) metabolism are lacking.

Case Description: A 49 year old, HIV-infected Caucasian male, presented in September 2014 with symptoms suggestive of ARV drug toxicity approximately 2 months post $\mathrm{HCV}$ diagnosis. The patient had been virally suppressed on a regimen of raltegravir (RAL) 400mg, lopinavir (LPV)/ritonavir (RTV) 400/100mg and maraviroc (MVC) $150 \mathrm{mg}$, all dosed twice daily plus lamivudine $300 \mathrm{mg}$ daily since 2011 with no complaints. Patient complained of nausea, dysgeusia (associated with high LPV concentrations), dizziness (associated with high MVC concentrations) and lethargy.

Assessment of Causality: TDM was carried out every two weeks, 4-5 hours post dose from September 2014 to February 2015 to determine possible correlation between liver function tests (LFTs) and drug concentrations. The patient's ALT was normal in May, then began to rise in June and reached a peak of 1192 U/L in September. MVC, LPV and RTV concentrations in September/October were greater than the population curves by up to $101 \%, 34 \%$ and $192 \%$, respectively. Increases in ALT generally correlated with increases in MVC, LPV and RTV concentrations.

Literature Review: LPV, MVC and RTV are metabolized by CYP3A4 while RAL is glucuronidated. Consistent with our observations, concentrations of drugs metabolized by CYP3A 4 such as diazepam and methadone have been shown to increase during acute viral hepatitis. There is no known change in metabolism of glucuronidated drugs such as oxazepam during acute viral hepatitis.

Importance to Practitioners: Additional research is needed to further elucidate the impact of acute hepatitis infection on ARV drug metabolism and the role of TDM.

\section{Evaluating Recall of Key Safety Messages, Attitudes and Perceptions of Patient Safety Initiative}

Sriram $D^{1,2}$, Cooke $C^{3}$, Vaillancourt $R^{1}$, Villarreal $G^{1}$, Pouliot $A^{1}$, Labelle $N^{4}$, Wrong $T^{3}$

${ }^{1}$ Department of Pharmacy, Children's Hospital of Eastern Ontario,

Ottawa, $O N$

${ }^{2}$ Carleton University, Ottawa, $O N$

${ }^{3}$ Department of Quality Management, Children's Hospital of Eastern Ontario, Ottawa, ON

${ }^{4}$ Volunteer Resources, Children's Hospital of Eastern Ontario, Ottawa, ON

Background: The Patient Safety Ambassador (PSA) program was developed to increase patient and parent/guardian engagement and knowledge of patient safety.

Purpose: The study aims to determine recall ability of key safety messages and explore attitudes and perceptions towards the PSA program.

Method: Patients aged 11-17 years old who had received the PSA visit 48 hours previously at the Children's Hospital of Eastern Ontario completed semi-structured interviews. Cued and non-cued recall was determined by using questions with and without specific cues. Attitudes on patient safety were evaluated using open-ended questions. The five key messages were: 1) Infection control protocols, including a) reminding healthcare staff to sanitize hands, b) parent and child sanitizing hands often, c) having parents/visitors staying at home if feeling ill, and d) following isolation protocols; 2) proper medication administration, including a) making sure the child keeps their ID bracelet on and b) ensuring healthcare worker checks the ID bracelet before administering medications; 3) prevention of falls from the bed, including a) parents staying within arm's reach of the child when bed rails are down and b) parents putting bed rails up when leaving the patient room; 4) utilization of the SPOT (Speech, Proactive, Outreach, Teaching) team; and 5) speaking up and asking questions.

Results: Significant findings revealed that $95 \%$ of the parents could remember all the safety messages with cues. However without cues, parents only remembered one $(35 \%)$ or two $(32.5 \%)$ of the messages. Teenage participants could remember up to 4 messages with cues, no messages without cues and were unable to discuss attitudes towards safety. 
Conclusion: Overall, the use of cues is beneficial in recalling safety messages. Additionally, parents had varying attitudes towards safety. Improvements for the PSA program include approaching teenagers and adults differently, integrating cues and using the teach-back method.

\section{Persistence and Compliance with Cardiovascular Drug Therapy among Seniors}

\author{
Arthur M, Proulx J, Hunt J, Gaucher M \\ Canadian Institute for Health Information, Ottawa, ON
}

Background: Cardiovascular disease is the second most common cause of death-behind only cancer-in Canada. Not taking medication as prescribed can lead to negative health outcomes for patients and additional costs to the health care system, as well as the wasted cost of the medication, whose full benefit is not being realized.

Objectives: To examine persistence and compliance with the most commonly used cardiovascular drug classes among seniors to assess the degree to which these drugs are being used as prescribed.

Methods: This study uses drug claims data from the National Prescription Drug Utilization Information System (NPDUIS) Database. The Database contains claims for roughly $70 \%$ of Canadian seniors. Persistence was measured by the amount of time a drug class was used before the presence of a gap in drug therapy that exceeded a pre-determined number of days. Compliance was measured by the proportion of days covered (PDC), calculated by summing the days' supply for a senior taking a single drug class over a one-year period.

Results: $72.9 \%$ of seniors taking selected cardiovascular drugs were considered persistent with their drug therapy, while $80.6 \%$ were considered compliant with their cardiovascular drugs. The largest $\mathrm{c}$ ontributor to non-persistence and non-compliance was starting a new cardiovascular therapy. Thiazide diuretics had a higher rate of nonpersistence and non-compliance than other classes, likely due to an increased number of side effects compared with other antihypertensive drugs.

Conclusion: While the majority of seniors appear to be taking their cardiovascular drugs as prescribed, some seniors may not be deriving full benefit from their prescribed medications. Improved medication management and education, shown to improve persistence and compliance and help reduce negative health outcomes, may be particularly valuable for patients starting a new cardiovascular therapy.

\section{Preventable Medication Incidents: Look-Alike/Sound-Alike Drug Names

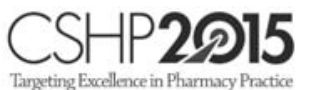

Kawano A, Li Q (K), Cao J, Ho C

ISMP Canada, Toronto, ON

Background: Drugs that are look-alike/sound-alike commonly results in medication incidents and may cause severe harm to patients. This is especially pronounced in patients with polypharmacy. The aim of this project is to identify potential contributing factors or causes for these incidents.

Description: A qualitative, multi-incident analysis was conducted using anonymous reports submitted to the Institute for Safe Medication Practices Canada (ISMP Canada) Community Pharmacy Incident Reporting (CPhIR) Program.
Action: Medication incidents involving "look-alike/sound-alike drug names" from April 2010 to March 2012 were included in the analysis; a total of 342 incidents met inclusion criteria.

Evaluation: The four areas of concern leading to errors were: (1) Individuals - Human capabilities and limitations such as confirmation bias, illegible handwriting and knowledge deficit are main drivers for errors. (2) Environmental - Work environment and workflow processes such as drug storage, environmental distractions and drug shortage. (3) Technological - Vigilance should be exercised with the use of shortcuts in pharmacy computer systems, such as copying prescriptions. (4) Unique factors that are specific to the look-alike/sound-alike drug pairs such as similar dose, indication, and same ingredients in multiple formulations. Standardized pre-printed order forms and the inclusion of both generic and brand names in pharmacy order entry system should be implemented for system-based improvements.

Implications: The causes of medication incidents from look-alike/soundalike drug names are multifactorial. It is important for health care professionals to recognize these vulnerabilities within our healthcare system and actively implement system-based improvements to mitigate the risks.

\section{Revising the GRASP® Workload Measurement Tool to Track Clinical Pharmacy Key Performance Indicators}

Chung $E^{1,2}$, Khaja $M^{1}$, Bjelajac Mejia $A^{1,2}$

${ }^{1}$ Department of Pharmacy, The Hospital for Sick Children, Toronto, ON

${ }^{2}$ Leslie Dan Faculty of Pharmacy, University of Toronto, Toronto, ON

Background: Recently, a set of clinical pharmacy key performance indicators (cpKPIs) were established in Canada. The cpKPIs measure hospital pharmacists' contributions to patient care, which aim to advance clinical pharmacy practice, and improve quality of patient care. We did not identify any published studies on revising existing workload measurement tools to capture cpKPIs.

Description: The GRASP® workload measurement tool is used at our institution to calculate the time spent on patient care activities. Some gaps in the tool that precluded cpKPI measurements were noted. Therefore, the GRASP® tool was revised to align with the cpKPIs.

Action: The GRASP® Tool Revision Working Group reviewed, analyzed and incorporated the cpKPIs into the GRASP® tool. Revisions included streamlining the electronic form, adding new items aligned with cpKPIs, and updating terminology. The revised tool was then implemented and validated.

Evaluation: Clinical productivity of twenty-four hospital pharmacists before and after implementation of the revised tool was compared. The combined clinical productivity increased from $77 \%$ to $101 \%$ after revisions of the tool. Majority of pharmacists had clinical productivity over $100 \%$ post-implementation. Most of clinical time was spent in patient assessment, resolution of drug therapy problems, and interprofessional rounds, which were similar pre- and post-revisions of tool. Usability of the tool was assessed by a staff satisfaction survey. Majority of pharmacists were satisfied and agreed that the revisions brought clarity to the items in the tool. Although majority agreed that the tool is more efficient, many commented on operating system limitations.

Implications: Documentation of workload hours improved after the revisions to the tool, and allowed for quantification of some cpKPIs. Clinical productivity indicated that pharmacists at our institution have a high workload. Future initiatives include incorporation of a cpKPI tracking method into the hospital's electronic clinical information system and revisions of our pharmacy scorecard. 


\section{The Development of an Advanced Pharmacy Practice Experience in Pharmacy Informatics \\ Sengar V, Lieu J, Satchu S \\ St Michael's Hospital, Toronto, ON}

Background: Pharmacy informatics is becoming an increasingly important role for pharmacists as hospitals move towards computerized provider order entry (CPOE) and electronic health records. Unfortunately, pharmacy students receive limited exposure to this expanding practice area.

Description: There are currently 2 pharmacy informatics specialists (PIS) at St. Michael's who are responsible for supporting various components of the medication management/CPOE system. It was hypothesized that some of the core activities performed by the PIS would be ideally suited for students to undertake and would provide them with the opportunity to gain an understanding of the medication system and the importance of pharmacy informatics.

Action: An advanced pharmacy practice experience (APPE) was developed and offered starting June 2014. A post-rotation survey was administered to all members of the clinical informatics team and student evaluations were reviewed.

Evaluation: To date, 2 students have completed APPEs. Combined, the students were able to complete optimization of 10 medication search screens, analysis of system impacts for 3 drug shortage items and content analysis for 3 order sets. This is compared to optimization of 1 medication search screen and revision of 4 order sets during the same time frame when no students were present. In addition to the application of therapeutic knowledge, students developed skills in data analysis and management, software utilization, communication and principles of system design. Members of the informatics team appreciated the quality and quantity of work completed. Both students agreed that pharmacy informatics was a relevant and rewarding rotation that would help them in their future practice and would recommend the rotation to future students.

Implications: This rotation offers students a unique opportunity to understand the importance of pharmacy informatics while making valuable contributions to patient care through optimization of the medication management/CPOE system. APPEs will continue to be offered in this practice setting.

\section{Evaluation of an Educational Intervention for Pharmacist Documentation Practices in a Tertiary Care Hospital}

MacInnis $M$, Herritt $L$ IWK Health Centre, Halifax, NS

Background: Timely and effective communication between heath care providers is an essential component of patient care. This is applicable to pharmacist drug therapy interventions as well as patient counseling activities. Pharmacist documentation in the health record will be a key component to the acceptance of pharmacist expanded scope activities in the hospital setting.

Description: Documentation practices of pharmacists were evaluated in 2014 for baseline data. An educational intervention was designed in consultation with Pharmacy Professional Practice Committee (PPPC). Documentation practices were re-evaluated one year after the baseline data collection.

Action: A workload measurement tool was used to identify pharmacist's interventions and a corresponding selection of charts was reviewed in 2014. Interventions were analyzed using a modified version of the
Canadian Society of Hospital Pharmacists (CSHP) document: "Tool to Evaluate Pharmacist's Skills for Documentation in the Health Record". Rate of documentation was determined. After the first year's result; an educational intervention was designed and administered. A 10 week long series of educational "e-blasts" was administered twice prior to reevaluating the intervention. A sampling of charts was audited in 2015 using the same methods and tool as the previous year.

Evaluation: Twenty-seven percent of the patient health records included pharmacist documentation; which represents a $4 \%$ decrease from the previous year. Reasons for documentation included clarifications and pharmacy suggestions. Clinical progress notes were absent and the majority of notes were written in the physician's order section.

Implications: An educational intervention was designed at the suggestion of the PPPC to address perceived barriers of lack of knowledge on documentation standards and to provide guidance for documentation in commonly encountered scenarios. This passive method of intervention failed to increase rate or quality of documentation by pharmacists. A more pro-active method of education and audit will be designed for the next year.

\section{Critical Care Pharmacist Pilot Project Tarreting Excellence in Pharmacy Practice}

Wells A, Gulka S, Gray C, Zulyniak L, Semchuk B, Bolt J Department of Pharmacy Services, Regina Qu'Appelle Health Region, Regina, SK

Background: Within our hospital, one decentralized pharmacist provides care to 22 critical care patients between 2 different units daily. We faced several challenges in the provision of care to this population; significant demands on pharmacist time beyond funded hours, inconsistency of pharmacist care as different pharmacist team members rotated through the area compounded by staff turnover, pharmacist frustration and burn out.

Description: The pilot was undertaken from October 2014 to March 2015. The primary goals of this project were assessment of current practice, pharmacist workload and best practices leading to implementation of practice changes required based on the assessments.

Action: We undertook a number of Plan-Do-Study-Act (PDSA) cycles related to workflow and patient care. We assessed a variety of workload variables both distribution and clinical in nature.

Evaluation: As a result of these PDSAs a number of initiatives were developed and implemented leading to improved workflow, time management and standardized pharmacist assessment and care:

1. alteration of existing Clinical Practice Standards

2. daily monitoring forms

3. seamless care communication forms

4. set times of availability on each unit

5. training module

The pilot project created efficiencies leading to a potential cost savings of approximately $\$ 11,000$ of overtime per year, without compromising patient care interventions.

Implications: The pilot project was able to increase efficiency, decrease overtime hours, standardize the role of the Pharmacist in Critical Care and establish a training module focused on increasing knowledge and confidence of staff pharmacists providing care to critically ill patients. We have since trained 5 pharmacists and have set the framework for our future care model, which also includes an Advanced Practice Pharmacist. 


\section{Developing and Implementing a Vision for Clinical Communication Using Pharmacy Information Systems in Hospitals}

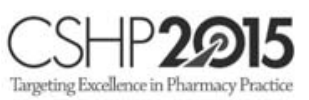

Thomson $P^{1,2,3}$, Fitch $P^{1,4,5}$, Davis $C^{6}$, Thompson $D^{1,7}$, McKenzie $L^{1}$

${ }^{1}$ Winnipeg Regional Health Authority Pharmacy Program, Winnipeg, MB

${ }^{2}$ Health Sciences Centre, Winnipeg, $M B$

${ }^{3}$ Faculty of Health Sciences, University of Manitoba, Winnipeg, MB

${ }^{4}$ Manitoba eHealth, Winnipeg, $M B$

${ }^{5}$ Victoria General Hospital, Winnipeg, $M B$

${ }^{6}$ St. Boniface Hospital, Winnipeg, $M B$

${ }^{7}$ Grace General Hospital, Winnipeg, $M B$

Background: Within our hospitals, communication methods for clinical activities varied between sites, programs and between pharmacists within each program group. Most communication methods were paper based and not compliant with the provincial Personal Health Information Act. These notes were often discarded on patient transfer. A team goal of the Pharmacy Program was standard documentation of clinical information within pharmacy information systems.

Description: A directive was developed from the Pharmacy Clinical Council to investigate methods of clinical documentation within pharmacy information systems. From this, four major initiatives were undertaken: discussions with Pharmacy Informatics, completion of a survey of current clinical documentation practice, drafting of a vision statement for review and discussion, and formation of a clinical documentation working group with front line representatives from all sites.

Action: The working group developed a list of what to document, reviewed priorities of clinical activities and approved a vision statement for electronic communication. The vision statement was patient focused and tied to relevant objectives from CSHP 2015. A subsequent working group for the sites using BDM Pharmacy (BDM) was formed to implement this vision within that application.

Evaluation: This working group evaluated methods to document clinical information within BDM. Each method was evaluated based on the above characteristics and the principles of documentation agreed to by the working group. Questionnaires were used to elicit feedback from front line staff during the trials. Challenges to implementation were identified; many were overcome by the working group.

Implications: Creating a vision resulted in a patient focused model for clinical communication. Responsibility was taken by front line pharmacists in the working group for creating and implementing the vision for clinical documentation in the BDM application. A number of opportunities exist to further expand the BDM clinical system. This remains a work in progress across all sites.

\section{Pre-operative Study Evaluating Patient Complexity with a Novel Pharmacy Triage Tool}

\section{CSHP2D15}

Delanghe $P^{1}$, Barbato $B^{1,2}$, Noormohamed $G^{1}$, Hewett $M^{1}$, Romeril $E^{1,3}$

${ }^{1}$ Hamilton Health Sciences, Hamilton, $O N$

${ }^{2}$ McMaster University, Hamilton, $O N$

${ }^{3}$ University of Waterloo, Waterloo, $O N$

Background: Pharmacists and pharmacy technicians provide medication reconciliation in a pre-operative setting. In a high volume pre-operative clinic setting, a triage system designed to guide patient referrals to see a pharmacist based on medication risk factors is desired.

Objective: The primary objective of this prospective, blinded, controlled study was to determine if a triage tool based on medication risk factors can accurately identify patients who would benefit from a pharmacy team referral.

Method: A patient survey form and triage tool was created based on published variables associated with adverse drug events. The primary outcome was prospective agreement between the triage tool intervention and a blinded pharmacist's decision control that a patient should be seen. For 13 days between April 7 and May 9, 2014, all eligible patients who attended the pre-operative clinic were asked to complete a self-reported 22 question form and a pharmacy team member reported separately the need for a referral. Patients were excluded if they were pediatric (age $<18$ ), pregnant, or declined to submit a form for any reason.

Results: A total of 524 patient forms and 506 pharmacy team assessments were completed. Agreement between the triage tool and the pharmacy team was $73 \%(95 \% \mathrm{CI}=0.69-0.77)$. Factor analysis results were used to optimize the triage tool agreement. During a second round of data collection, 356 patient forms and 489 pharmacy team assessments were completed. The primary endpoint of $80 \%(95 \% \mathrm{CI}=0.75-0.84)$ agreement was reached using a series of decision rules.

Conclusion: A novel patient self-reported triage tool was developed for pharmacy team use in a pre-operative setting. A 19 question survey with 7 specific decision rules demonstrated a high accuracy of identifying referrals. In the future, patients may use an electronic survey tool to guide referrals to see a pharmacist prior to surgery for a medication consultation.

\section{Evaluation of a Provincial Hospital Formulary Review Process}

Liston $H^{1}$, Louis $F^{2}$, Coombs $M^{1}$

${ }^{1}$ Pharmaceutical Services, Department of Health, Government

of New Brunswick, Fredericton, NB

${ }^{2}$ Horizon Health Network, Fredericton, NB

Background: In order to meet the requirements for a single hospital formulary outlined in the 2009 Provincial Health Plan, a single Drugs and Therapeutics Committee (D\&T) with supporting subcommittees was established. The goal was to help ensure equality of service, seamless transition between hospitals, more efficient use of available expertise and resources while aligning with the provincial drug plan formulary where possible.

Objectives: To evaluate the newly implemented province-wide hospital formulary review process as an important first step in assessing the reliability, transparency, and overall perception of formulary decisionmaking, communication, and implementation.

Methods: Two surveys were developed to capture feedback across several domains relevant to D\&T and the subcommittees including: Drug evaluation and class synopsis reports; Pharmacoeconomic data; Processes supporting recommendations and motions; Opportunity for discussion; and Implementation. The surveys were administered anonymously through an electronic platform.

Results: A total of 83\% (30/36) D\&T members, and 70\% (21/30) subcommittee members completed the respective surveys. At least $80 \%$ of the D\&T Committee and subcommittee respondents indicated they either agreed or strongly agreed with current processes across the majority of questions. This was not the case for several questions primarily related to the interchange of information including garnering stakeholder feedback, additional information relevant to reports, usefulness of budget 
impact analyses, information on implementation of decisions, and knowledge transfer to physicians and other stakeholders.

Conclusion: Survey responses indicated that the current structured process was largely effective. Areas identified for further action and consideration involved how and what information is collected, presented, discussed and communicated including the transfer of information to physicians and other stakeholders across hospitals within the province.

\section{Impact of PharmaNet-Based Admission Medication Reconciliation on Warfarin Best Possible Medication Histories}

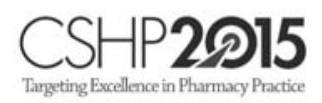

Au $D^{1}$, Wu $H^{2}$, Chua $D^{2}$, Su $V^{2}$, San $C^{2}$, Chan $S^{2}$, Fung $A^{3}$

${ }^{1}$ Lower Mainland Pharmacy Services, Vancouver, BC

${ }^{2}$ St Paul's Hospital, Vancouver, BC

${ }^{3}$ University of British Columbia, Vancouver, $B C$

Background: Medication discrepancies commonly occur during transitions of care as a result of inaccurate medication history documentation. Obtaining the best possible medication history (BPMH) for warfarin can be challenging due to frequent dosage changes and nonspecific directions of use by prescribers. Our hospital implemented an admission medication reconciliation (MedRec) process using a form that compiles the most recent 6 months of outpatient prescription dispensing history from an electronic database called PharmaNet. It is unclear whether MedRec has improved the quality of warfarin BPMH documentation and has reduced the rates of warfarin-related adverse events during hospital stays.

Objectives: To compare the rates of complete warfarin BPMH documentation, rates of major bleeding and thromboembolic events, and percent time in therapeutic INR range in hospital before and after implementation of PharmaNet-based admission MedRec.

Methods: A retrospective chart review of patients on warfarin therapy who were admitted to our hospital's Internal Medicine Service was performed. Patients were excluded if they did not have a PharmaNet record, were transferred to a critical care ward, received surgery, were discharged or transferred to another facility within 24 hours, or were admitted with a major bleeding or thromboembolic event. Chi-squared and Mann-Whitney $U$ tests were used to analyze categorical and non-parametric continuous data, respectively.

Results: Data was recorded for 100 patients in the pre-implementation phase and 100 patients in the post-implementation phase of Pharmanetbased admission MedRec. The rates of complete warfarin BPMH documentation were $65 \%$ and $84 \%$ in the pre- and post-implementation phases, respectively $(\mathrm{p}=0.002)$. There were no statistically significant differences in rates of major bleeding, rates of thromboembolic events, or percent time in therapeutic INR range in hospital.

Conclusion: The implementation of PharmaNet-based admission MedRec improved the rate of complete warfarin BPMH documentation, but no differences in warfarin safety and efficacy outcomes were observed.

\section{Restriction of Codeine Prescribing in Patients Less than 18 Years Old: Policy to Provide Safer Pain Management in Paediatric Population}

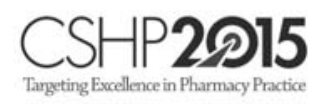

Beaman $A^{1}$, Mah $C^{1}$, Tugwood $B^{2}$, Tran $T^{2}$, Mills $A W^{1,2}$

${ }^{1}$ Credit Valley Hospital - Trillium Health Partners, Mississanga ON

${ }^{2}$ Mississanga Hospital - Trillium Health Partners, Mississanga ON

Background: Codeine is a pro-drug, metabolized to morphine via CYP2D6, with weak opioid activity and limited efficacy for treatment of mild-moderate pain. A high degree of genetic polymorphism in the CYP2D6 enzyme results in unpredictable analgesic and adverse effects. As high as $10-30 \%$ of patients may be ultra-rapid metabolizers and will convert codeine more rapidly and completely to morphine, resulting in $50 \%$ higher plasma morphine concentrations and risk of morbidity and mortality. Case reports of fatalities in toddlers have made national news.

Description: The Paediatric Program made a formal recommendation to the Pharmacy \& Therapeutics and Medical Advisory Committees to restrict codeine prescribing organization-wide to exclude patients less than 18 years old. We are a community hospital encompassing three main sites, offering acute care hospital services (approximately 1000 inpatient beds), and community-based, specialized programs, and an affiliation with a medical teaching program.

Action: Steps taken by an inter-disciplinary group included:

1. Assessment of practice areas at risk.

2. Education and tools for staff providing care to paediatric patients

3. Outreach to retail pharmacies serving our community.

4. Automated electronic alerts.

5. Prescription forms revisions.

Evaluation: A one-week audit of paediatric codeine orders was conducted to assess the effectiveness of the interventions. We observed only two codeine orders for inpatients, and pharmacists changed therapy to morphine. Morphine was dosed conservatively overall, although pain control was acceptable in all cases.

Implications: We have been successfully able to eliminate codeine from formulary for paediatric patients. Challenges encountered in implementing this patient safety initiative were to engage prescribers across the organization to recognize the safety concerns, and gathering consensus from prescribers with different practices from across the organization. We still face challenges in assessing discharge prescribing patterns, and for pain control in adolescents.

\section{Incidence, Management and Sequelae of Out-of- range INR values in a New Anticoagulation Clinic in Qatar}

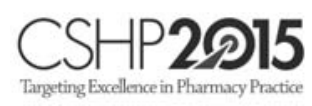

Abdu A, Fahmi A, Abdelsamad O

Anticoagulation Clinic, Al Wakra Hospital,

Hamad Medical Corporation, Qatar

Background: Incidence of out-of-range INR values in patients on warfarin is associated with increased risk of adverse events (namely bleeding and new thrombotic events). This incidence also is a key quality measure of anticoagulation clinics. Our setting is a newly initiated 
pharmacist-managed anticoagulation clinic and it is one of the first experiences in the Arabian Gulf.

Objectives: To study the incidence of significant out-of-range INR values in a new anticoagulation clinic, how patients with these INR values are managed and if there are associated bleeding or new thrombotic events with these INR values. Knowledge of these outcomes will help evaluate and improve the services provided in pharmacist-managed anticoagulation clinics.

Methods: A retrospective service evaluation study was carried out in the new anticoagulation clinic in Al Wakra Hospital. Participants were patients with nonvalvular atrial fibrillation on a maintenance warfarin regimen. Patients with newly initiated or recently interrupted regimens were excluded. Clinical pharmacists who are managing the clinic were to acknowledge patients' INR values, carry out management plans and document any clinical events experienced. Outcomes included incidence of significant out-of-range INR values (INRs $<1.7$ or $>4$ ) and incidence of significant bleeding or new thrombotic events.

Results: Data was collected for the period April to June 2014. 22 eligible patients were enrolled with 75 eligible INR values. Incidence of significant out-of-range INR values was $20 \%$ (15 out of 75 INR readings). 2 of the 22 patients $(9 \%)$ experienced bleeding events that warranted interruption of warfarin but no reversal needed. No patients experienced new thrombotic events.

Conclusion: Incidence of significant sub or supra-therapeutic INR values was within internationally reported figures, and was associated with low incidence of bleeding events, and no new thrombotic events. These findings show a good anticoagulation control of nonvalvular AF patients following up in a new pharmacist-managed anticoagulation clinic.

\section{Development of an Educational Program for Hospital Pharmacists Focused on Drug Information and Evidence-Based Medicine}

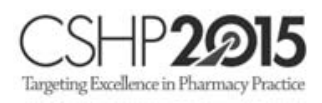

Cheung $L^{1,3}$, Zolezzi $M^{2}$, Fitzgerald $K^{3}$

${ }^{1}$ University of Alberta Faculty of Pharmacy and Pharmaceutical Sciences,

Edmonton, $A B$

${ }^{2}$ College of Pharmacy, Qatar University, Doha, Qatar

${ }^{3}$ Pharmacy Services, Alberta Health Services, Edmonton, AB

Background: Drug information (DI) and literature evaluation are essential skills for pharmacists in order to practice evidence-based medicine (EBM). However, developing these skills beyond the basics can be challenging, especially for those trained prior to the advent of the Internet.

Description: The clinical pharmacy leadership team developed an educational program for pharmacists to address EBM knowledge gaps. The educational program was offered as a series of self-directed learning modules (basic, intermediate and advanced) in power-point form.

Action: A self-assessment questionnaire on DI and EBM knowledge was completed by various pharmacists and showed that individual learning needs were very diverse in these areas. The educational program was developed based on pharmacists' self-assessment, in consultation with the clinical pharmacy leadership team. The aim was to develop a series of modules that were self-directed, so that each pharmacist could address his/her own individual learning needs. The content of the modules were further designed after an exhaustive literature search and consultation with library services.
Evaluation: Pharmacists who participate in the educational program are guided by a clinical practice leader (CPL) before, during, and after completing a DI module. CPLs are responsible for assisting pharmacists in translating relevant acquired knowledge and skills to their individual practice setting. Pharmacists complete a post self-assessment questionnaire to assess whether the module is clear, effective, and useful in helping them meet the learning objectives outlined. Thus far, pharmacist feedback via post questionnaires has been positive.

Implications: The DI modules provide pharmacists with varying educational backgrounds and DI retrieval abilities with the opportunity to build fundamental EBM skills. It is hoped that through this ongoing development, pharmacists will begin to participate in activities that they were previously uncomfortable with, such as facilitating discussions regarding new evidence in their clinical practice area or application of new evidence into patient care.

\section{Development and Evaluation of an Anticoagulation Education Resource for Patients

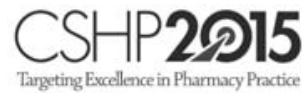

Cheung $L^{1,3}$, Zolezzi $M^{2}$, Wright $C^{3}$

${ }^{1}$ University of Alberta Faculty of Pharmacy and Pharmaceutical Sciences,

Edmonton, $A B$

${ }^{2}$ College of Pharmacy, Qatar University, Doha, Qatar

${ }^{3}$ Alberta Health Services, Edmonton, $A B$

Background: Hospitals are required to implement standardized anticoagulation practices to reduce adverse drug events and improve patient outcomes according to various entities, including the Institute for Safe Medication Practices and the Centers for Medicare and Medicade Services.

Description: The pharmacy department developed a video for the stroke rehabilitation unit about oral anticoagulants, which included a section about warfarin as well as a section about new anticoagulation agents. Handouts were used to supplement information in the video and pharmacists/nurses were available to patients in order to reinforce comprehension.

Action: The information in the video was produced via consultation with a multidisciplinary team as well as available anticoagulation resources. Both pharmacist and nurse educators were trained to administer the video to patients whom they would identify. Patients could watch the video on a portable device, DVD player, or computer and could watch at their own pace. Educators who administered the videos were expected to provide patients with additional resources as necessary, as well as follow up with a conversation to fill knowledge gaps.

Evaluation: A "pre"- questionnaire was completed by patients prior to watching the video to assess patient's existing knowledge regarding oral anticoagulation. Patients who watched the video completed a "post"questionnaire, which assessed patient knowledge after watching the video. Following the video, most patients claimed to have a basic understanding of oral anticoagulants and patient knowledge increased regarding the purpose, side effects, diet restrictions, and monitoring parameters of their anticoagulation medication.

Implications: The anticoagulation video provides patients with essential and standardized information about their anticoagulation medications. It is hoped that through this initiative, patients will take more responsibility for and adhere to an anticoagulation plan of care, thus improving patient outcomes and reducing adverse drug events. 


\section{Feasibility of Monitoring Real-Time Temperatures of Medications in a Ground Ambulance System: A Pilot Study}

\author{
Deveau $B^{1,2}$, Stewart $P^{2}$, Jensen ${ }^{2}$, Agu $R^{1}$ \\ ${ }^{1}$ College of Pharmacy, Dalhousie University, Halifax, NS \\ ${ }^{2}$ Emergency Health Services, Halifax, NS
}

Introduction: Many emergency medical services (EMS) agencies do not monitor temperatures of the environment where medications are stored. Medications stored at bases and in ambulances often lack climate control, which could lead to a loss of medication stability.

Objectives: The objective is to determine the feasibility of remotely monitoring temperatures, to describe temperatures observed, and to determine how often medication temperatures exceed recommended limits.

Methods: We conducted a 5-week pilot study in a provincial ambulance system. Temperature tags were placed in 134 ambulance medication cabinets and 162 on scene medication bags. A sample of 15 Tenecteplase (TNK) storage thermoses and 15 intubation kits containing topical anesthetics had tags placed. Temperatures and number of times temperature exceeded predetermined thresholds were monitored. Temperature thresholds were defined as beyond $15-30^{\circ} \mathrm{C}$. Due to TNK temperature guidelines, temperatures beyond $8^{\circ} \mathrm{C}$ and $15^{\circ} \mathrm{C}$ were analyzed.

Results: Data was collected from 134 ambulance medication cabinets (45.3\%). Mean temperature was $23.3^{\circ} \mathrm{C}\left(95 \% \mathrm{CI}, 24.3-24.4^{\circ} \mathrm{C}\right.$, range 6.0-40.7 ${ }^{\circ} \mathrm{C}$ ). Temperatures exceeded $25^{\circ} \mathrm{C} 35,375$ times $(30.0 \%), 30^{\circ} \mathrm{C}$ 1,752 times $(1.5 \%)$, and $35^{\circ} \mathrm{C} 76$ times $(0.1 \%)$. Data was obtained from 162 on scene medication bags $(54.7 \%)$. Mean temperature was $23.9^{\circ} \mathrm{C}$ $\left(95 \% \mathrm{CI}, 23.8-23.9^{\circ} \mathrm{C}\right.$, range $\left.6.5-45.4^{\circ} \mathrm{C}\right)$. Temperatures exceeded $25^{\circ} \mathrm{C}$ 33,048 times $(24.0 \%), 30^{\circ} \mathrm{C} 2,356$ times $(1.7 \%)$, and $35^{\circ} \mathrm{C} 168$ times $(0.1 \%)$. Data was acquired from 15 thermoses containing TNK $(100 \%)$. Mean temperature was $24.0^{\circ} \mathrm{C}\left(95 \% \mathrm{CI}, 23.9-24.0^{\circ} \mathrm{C}\right.$, range 6.5-31. $\left.7^{\circ} \mathrm{C}\right)$. Temperatures exceeded $8^{\circ} \mathrm{C} 8,335$ times $(99.8 \%), 15^{\circ} \mathrm{C}$ 8,146 times $(97.0 \%), 25^{\circ} \mathrm{C} 1,521$ times $(18.0 \%), 30^{\circ} \mathrm{C} 27$ times $(0.3 \%)$, and $35^{\circ} \mathrm{C} 0$ times. Data from 15 intubation kits (100\%) showed a mean temperature of $24.0^{\circ} \mathrm{C}\left(95 \% \mathrm{CI}, 23.9-24.1^{\circ} \mathrm{C}\right.$, range $\left.6.5-32.0^{\circ} \mathrm{C}\right)$. Temperatures exceeded $25^{\circ} \mathrm{C} 1,915$ times $(22.0 \%), 30^{\circ} \mathrm{C} 28$ times $(0.3 \%)$, and $35^{\circ} \mathrm{C} 0$ times.

Conclusion: This pilot study found remotely collected temperatures feasible. Data from the study was used to guide EHS medication storage policy recommendations.

\section{Community Pharmacist Perception and Utilization of a Pediatric Emergency Department Asthma Action Plan and Prescription}

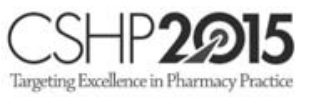

Stulberg $E^{1,2}$, Irwin $D^{1,3}$, Vaillancourt $R^{1}$, Zemek $R^{3}$, Farion $K^{3}$, Rohde $K^{4}$ ${ }^{1}$ Pharmacy Department, Children's Hospital of Eastern Ontario, Ottawa, ON

${ }^{2}$ Leslie Dan Faculty of Pharmacy, University of Toronto, Toronto, ON ${ }^{3}$ Emergency Department, Children's Hospital of Eastern Ontario, Ottawa, ON

${ }^{4}$ Research Institute, Children's Hospital of Eastern Ontario, Ottawa, ON

Background: Asthma action plans are a key component in the care for all asthma patients. We established and validated an Asthma Action Plan and Prescription (AAPP) that incorporated validated pediatric-specific pictograms. Pharmacists in the community have the opportunity to provide asthma counselling using this AAPP.
Purpose: The goal was to assess community pharmacists' perceptions and utilization of this novel AAPP as an educational resource.

Method: The study included community pharmacists practicing within a $10 \mathrm{~km}$ radius of our tertiary pediatric hospital in Ottawa Ontario that used the AAPP for at least a 3 month period. Participants completed an in-person questionnaire with open-ended questions, and Likert scales were used to assess perceptions regarding appearance, content, and usability of the AAPP.

Results: Out of a total of 201 pharmacies identified, 71 pharmacies were randomly contacted for participation, for which 60 pharmacists agreed to participate. Our findings showed that pharmacists responded positively (either agreed or agreed strongly) to appearance (96\%), content (98\%) and usability for patient counselling (93\%). Overall, $94 \%$ of pharmacists mentioned the likelihood of them implementing the AAPP into their everyday practice.

Conclusion: Pharmacists perceive the AAPP as a useful tool to provide counseling to pediatric asthma patients. Perceptions of AAPP by patients and parents discharged from the ED following an acute asthma exacerbation should be included in future research.

\section{Tolerability and Efficacy of Basiliximab as Induction Therapy to Prevent Cardiac Transplant Rejection: A Systematic Review}

San $C^{1}$, Chua $D^{2}, S u V^{2}$

${ }^{1}$ Faculty of Pharmacy, University of Alberta, Edmonton, $A B$

${ }^{2}$ St Paul's Hospital, Vancouver, $B C$

Background: In North America, induction therapy with antithymocyte globulin (ATG) and rabbit antithymocyte globulin (RATG) are traditionally used in cardiac transplantation to prevent rejection. However, they are poorly tolerated and increase the risks of lymphoma and infection. Basiliximab, a newer class of anti-interleukin-2 inhibitors, is approved in Canada for use as induction therapy in cardiac transplantation to prevent rejection. Current Canadian and international cardiac transplant guidelines do not provide recommendations on the agent of choice for induction therapy.

Objectives: To systematically review the literature and determine 1) the safety and tolerability and 2) efficacy of basiliximab as compared to other induction agents in cardiac transplant

Methods: MEDLINE, PubMed, Cochrane databases were searched using the terms "heart transplant", "cardiac transplant", "basiliximab", "interleukin-2 inhibitor", "IL-2Ra" and "anti-CD25". All studies that compared basiliximab to another induction agent in adult cardiac transplant with clinical outcomes were included. Pediatric cardiac transplant, meta-analyses, case reports and studies using induction agents that are not commercially available were excluded.

Results: See page 357.

Conclusion: Based on the available evidence, basiliximab 20mg IV on day 0 and 4 of cardiac transplant is better tolerated compared to ATG or RATG. The evidence for efficacy of basiliximab compared to ATG or RATG in terms of rejection and survival is conflicting. Limitations of the available studies are its retrospective nature, differing immunosuppressive regimens in each treatment group, varied definitions of clinical endpoints and small sample size. Further prospective trials are warranted to determine the efficacy of basiliximab compared to ATG or RATG. 


\section{SES 2015 POSTER ABSTRACTS / RÉSUMÉS DES AFFICHES DES SÉÉ 2015}

\begin{tabular}{|c|c|c|c|c|c|c|c|}
\hline $\begin{array}{l}\text { Results: } \\
\text { Study }\end{array}$ & Design & Intervention & Comparator & Outcome & Intervention & Control & p \\
\hline Whitson et al. 2015 & $\begin{array}{l}\mathrm{N}=6,464 \\
\text { Retrospective data } \\
\text { registry 1987-2012 }\end{array}$ & Basiliximab/daclizumab & ATG & Survival & \multicolumn{2}{|c|}{$\begin{array}{c}\text { HR } 0.948 \\
95 \% \text { CI }(0.85-1.06)\end{array}$} & 0.341 \\
\hline \multirow[t]{2}{*}{$\overline{\text { Chou et al. } 2008}$} & \multirow[t]{2}{*}{$\begin{array}{l}\mathrm{N}=43 \\
\text { Single center, } \\
\text { retrospective cohort } \\
2006-2007\end{array}$} & \multirow[t]{2}{*}{$\begin{array}{l}\text { Basiliximab 20mg IV } \\
\text { day } 0 \text { and } 4\end{array}$} & \multirow[t]{2}{*}{$\begin{array}{c}\text { RATG } 1.5-2.5 \mathrm{mg} \text { IV } \\
\text { day } 0,1 \text { and } 2\end{array}$} & $\begin{array}{c}\text { Acute rejection }>2 \mathrm{R} \\
\text { or rejection with } \\
\text { hemodynamic compromise } \\
\text { (\# patients) }\end{array}$ & 0 & 3 & NR \\
\hline & & & & Infection (\# patients) & 6 & 11 & 0.75 \\
\hline \multirow[t]{2}{*}{ Mattei et al. 2007} & \multirow[t]{2}{*}{$\begin{array}{l}\mathrm{N}=80 \\
\text { Prospective open } \\
\text { labeled, multicenter } \\
\text { study 2002-2004 }\end{array}$} & \multirow[t]{2}{*}{$\begin{array}{l}\text { Basiliximab 20mg IV } \\
\text { day } 0 \text { and } 4\end{array}$} & \multirow[t]{2}{*}{$\begin{array}{l}\text { ATG } 2.5 \mathrm{mg} / \mathrm{kg} \text { daily } \\
\text { for } 3-5 \text { days }\end{array}$} & $\begin{array}{l}\text { Composite safety endpoint } \\
\text { at } 6 \text { months (serum sickness, } \\
\text { fever, rash, anaphylaxis, } \\
\text { infection, thrombocytopenia, } \\
\text { leucopenia, post-transplant } \\
\text { proliferative disease) }\end{array}$ & $50 \%$ & $78 \%$ & 0.01 \\
\hline & & & & $\begin{array}{l}\text { Composite efficacy endpoint } \\
\text { at } 6 \text { months (death, graft loss, } \\
\text { acute rejection }>1 \mathrm{~B}, \\
\text { acute rejection with } \\
\text { hemodynamic compromise } \\
\text { or treated with antibody } \\
\text { therapy) }\end{array}$ & $63.3 \%$ & $66.7 \%$ & NS \\
\hline Carrier et al. 2007 & $\begin{array}{l}\mathrm{N}=35 \\
\text { Prospective, randomized, } \\
\text { multicenter non- } \\
\text { inferiority study } \\
2002-2004\end{array}$ & $\begin{array}{l}\text { Basiliximab 20mg IV } \\
\text { day } 0 \text { and } 4\end{array}$ & $\begin{array}{c}\text { RATG } 125 \mathrm{mg} \text { IV } \\
\text { day } 0,1 \text { and } 2\end{array}$ & Rejection $>3 \mathrm{~A}$ at 6 months & $65 \%$ & $83 \%$ & $0.55^{*}$ \\
\hline \multirow[t]{2}{*}{ Flaman et al. 2006} & \multirow{2}{*}{$\begin{array}{l}\mathrm{N}=48 \\
\text { Single center, } \\
\text { retrospective cohort } \\
2002-2005\end{array}$} & \multirow[t]{2}{*}{$\begin{array}{l}\text { Basiliximab 20mg IV } \\
\text { day } 0 \text { and } 4\end{array}$} & \multirow[t]{2}{*}{$\begin{array}{c}\text { RATG } 1.5 \mathrm{mg} / \mathrm{kg} \text { IV } \\
\text { day } 0-2\end{array}$} & $\begin{array}{l}\text { Average biopsy score } \\
\text { at } 1 \text { month }\end{array}$ & 0.79 & 0.47 & 0.023 \\
\hline & & & & $\begin{array}{c}\text { Average biopsy score } \\
\text { at } 6 \text { months }\end{array}$ & 0.97 & 0.58 & 0.14 \\
\hline
\end{tabular}

*non-inferiority could not be shown

$\mathrm{NR}=$ not reported, $\mathrm{NS}=$ not significant 